\title{
Semi-Deep Skirted Foundations and Numerical Solution to Evaluate Bearing Capacity
}

\author{
Keivan Esmaeili, Abolfazl Eslami, Samiyeh Rezazadeh \\ Department of Civil and Environmental Engineering, Amirkabir University of Technology (Tehran Polytechnic), Tehran, Iran \\ Email: afeslami@aut.ac.ir
}

How to cite this paper: Esmaeili, K., Eslami, A. and Rezazadeh, S. (2018) Semi-Deep Skirted Foundations and Numerical Solution to Evaluate Bearing Capacity. Open Journal of Geology, 8, 623-640. https://doi.org/10.4236/ojg.2018.86036

Received: March 28, 2018

Accepted: June 18, 2018

Published: June 21, 2018

Copyright (c) 2018 by authors and Scientific Research Publishing Inc. This work is licensed under the Creative Commons Attribution International License (CC BY 4.0).

http://creativecommons.org/licenses/by/4.0/

(c) (i) Open Access

\begin{abstract}
Semi-deep foundations are a remarkable solution in conditions where the soil beneath the foundation is loose to a great depth and there is no possible way to use any way of soil improvement and applying piles would not be a logical way considering their cost and time of enforcing. Skirted foundations are a type of semi-deep foundations that can penetrate to the soil up to two times of their breadth. Estimating bearing capacity of these foundations is a long geotechnical problem for engineers whether under absolute or combined loading because of their usage in offshore and onshore projects. For estimating the vertical bearing capacity of these foundations, series of finite element analyses were performed for a range of embedment ratios to investigate the effect of the length of the skirt. The foundation has been modelled with two different types of soil and the results validated with previous analytical, numerical and experimental researches. In addition, the bearing capacity of a skirted foundation under combined loading in $V-H$ space has been analyzed by this approach and the 2-dimentional failure envelope has been presented.
\end{abstract}

\section{Keywords}

Semi-Deep Foundation, Bearing Capacity, Load-Displacement Curve, Embedment Depth Ratio, Failure Envelope

\section{Introduction}

One of the most important stages of designing structures is analyzing and calculating the foundation of them. Foundation is the inductor element that the duty of transferring load from substructure to soil is on it. Therefore, it can be realized that foundation is the most vital part of a structure. Optimal design and analysis of a foundation consist of five basic requirements such as:

1) Determining bearing capacity 
2) Estimating the amount of settlement

3) Structural design

4) Control stability

5) Executive and economic aspects

Generally, there are three types of foundations called:

1) Shallow foundations

2) Semi-deep foundations

3) Deep foundations (piles)

Shallow foundations are the typical footings that in most cases their embedment depth is less than their breadth. These types of foundations are useless in great projects because of their disability in supplying enough bearing capacity and their non-uniform settlement under massive pressures and forces.

Unlike the shallow foundations, deep foundations or piles are so applicable for great projects because they can penetrate into the soil more than ten times of their breadth, however, these foundations have some disadvantages as well. Piles have high expenses and their installing and enforcing is extremely time-consuming.

In this paper, an intermediate solution has been presented, which is hybrid or semi-deep foundations that can penetrate up to four times of their breadth into the soil. Therefore, they can improve the bearing capacity and fix most requirements of optimizing foundation design.

Skirted foundations are one of the most applicable semi-deep foundations in onshore projects and oil and gas and other industries. To evaluate their bearing capacity, a numerical approach with finite element analysis is suggested in this paper. To calculate the bearing capacity of a skirted foundation under combined loading, fist it is needed to realize what would happen to these foundations under absolute vertical loading. The parameters that affect the bearing capacity should be investigated to estimate the amount of bearing. The foundation's geometry especially the amount that skirt penetrate into the soil is the most considering parameter that affects the bearing capacity of the foundation because it would pass the soft layers of the soil and reach to the layers with acceptable roughness.

Several analytical, numerical and experimental researches have been carried out in last two decades by different researchers on bearing capacity of skirted foundations under absolute and combined loading such as: upper and lower bound analyses by Bransby \& Randolph (1999) [1], finite element analyses and centrifuge test by Yun \& Bransby (2007) [2], skirted foundations in plane strain by Gourvenec (2008) [3] and finite element and upper bound plasticity analyses by Eslami \& Rezazadeh (2017) [4].

Therefore, the main goal of this study is presenting a numerical method for evaluating the bearing capacity of skirted foundations under absolute and combined loading in soft clay deposits whether in offshore or onshore projects. To do this, several finite element analyses have been done on the skirted foundations with different embedment depth ratios from 0.2 to 2 . In uniform soil and 
soil with incremental shear strength with depth. In addition, the bearing capacity of the skirted foundation under combined loading has been analyzed by finite element method in uniform soil in $V-H$ space in order to present a failure envelope.

\section{Semi-Deep Foundations}

These foundations are used to apply for better transfer of load and passing through soft and loose layers of soil surface by penetrating into the soil down to two or four times of the breadth of the foundation $\left(D_{f}=2 B-4 B\right)$. They will improve the foundation capacity and decrease settlement. In this paper, it is aimed to express types of these foundations and investigate on their properties.

\subsection{Floating Foundations}

Floating foundations are one of the considerable improvements in optimizing the foundations in the last decades that consist of placing the footing into the depth of the soil with or without pile that cause better performance in bearing capacity and settlement (Golder (1976) [5]). In cases where the substructure is heavier and have a particular importance, the foundation system should have a particular bending rigidity. When the soft soil deposits with high prone to settlement form the layers of soil up to relatively high depth and there is not any possible way to use pile, floating foundations are a good solution (Figure 1).

\subsection{Well Foundations}

In cases that using any ways of soil improvement for amending the soil condition is impossible, well foundations could be used. For implementing a well foundation, a hollow shaft or a box will submerge into the ground until it reaches to a rough layer of the soil (Gupta (2007) [6]). To make the merging of the box to the soft soil easier, cutting edge will improvise below the box. After lying the lower edge on the rough layer, the materials inside the box will be unloaded and then concreting it after putting the armature rack into it (Figure 2).

\subsection{Pier Foundations}

Pier foundations or Bucket foundations or Cassions are actually in place concrete piles that their diameter is more than 750 millimeters and in some cases, it reaches even a few meters. These foundations do not have the problems of

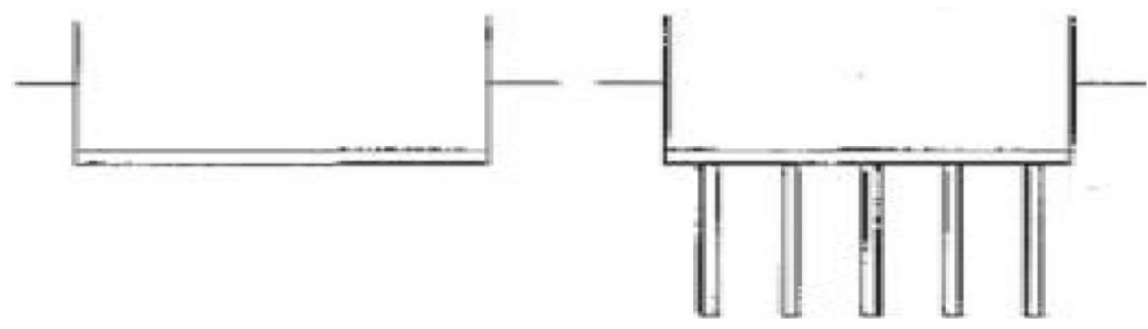

Figure 1. Shape of a floating foundation with or without pile. 

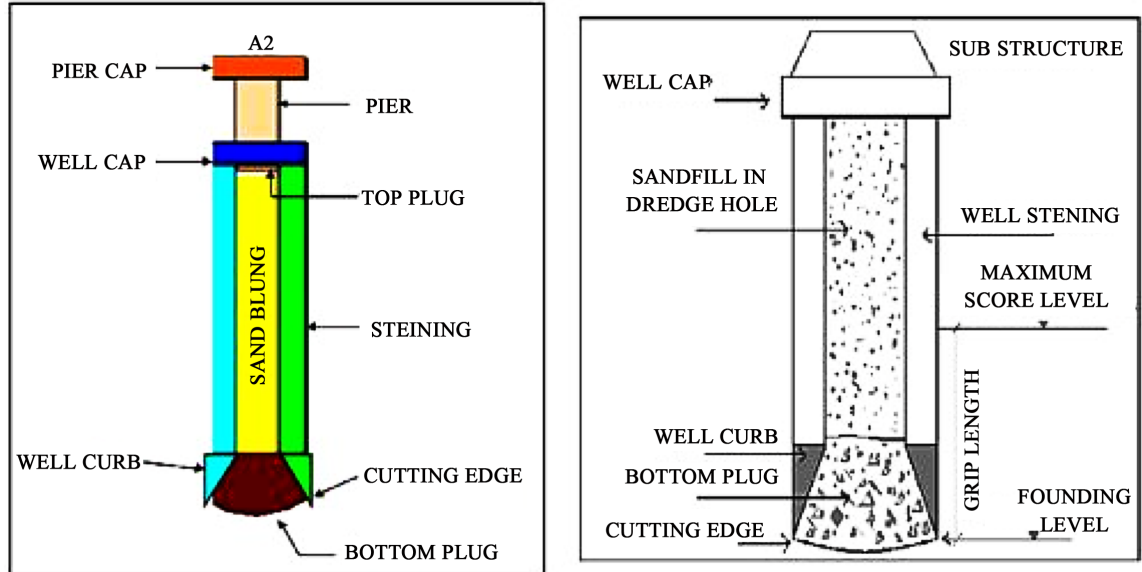

Figure 2. Details of a well foundation.

enforcing driven piles such as much noise and relocating soil. Other significant benefit of these foundations is that they can bear the great tensile and lateral forces because of their roughness and big diameter. These foundations could be installed with suction system. Suction will increase the effective stress and finally the shear strength of the soil (Saleh (2008) [7], Barari (2012) [8], Ibsen (2015) [9]) (Figure 3).

\subsection{Spudcan and Jack-Up}

The great circular Spudcans with the floating platforms that is called Jack-up are one of the most useful foundations in offshore industries. These foundations can penetrate several diameters into the soft seabed deposits that cause their difference in failure mechanism and bearing capacity in comparison with surface footings (Figure 4).

\subsection{Pile-Raft Foundations}

This type of semi-deep foundations is consist of a raft footing along with a pile or group of piles. Typically, these foundations are categorized in two groups. The first group is the raft relies on the pile or piles that is in most conditions that raft foundations have settled directly on the soil surface and the other is the raft that reinforced with pile and piles that is used when the soil at surface layers is so loose and the raft part faces with additional settlements. This is the time that piles should help raft in bearing loads. Pile-raft foundations have four important interaction systems including; raft with pile group, raft with soil, piles with soil, and piles with each other (Mekbib (2004) [12], Davis (1972) [13], Eslami (2011) [14]) (Figure 5).

\subsection{Skirted Foundations}

Skirted foundations consist of a raft-type foundation of breadth, B on the soil surface along with thin vertical plates or skirts connected to the raft perimeter penetrating the soil to a depth, D. By penetrating into the soil up to two times of 


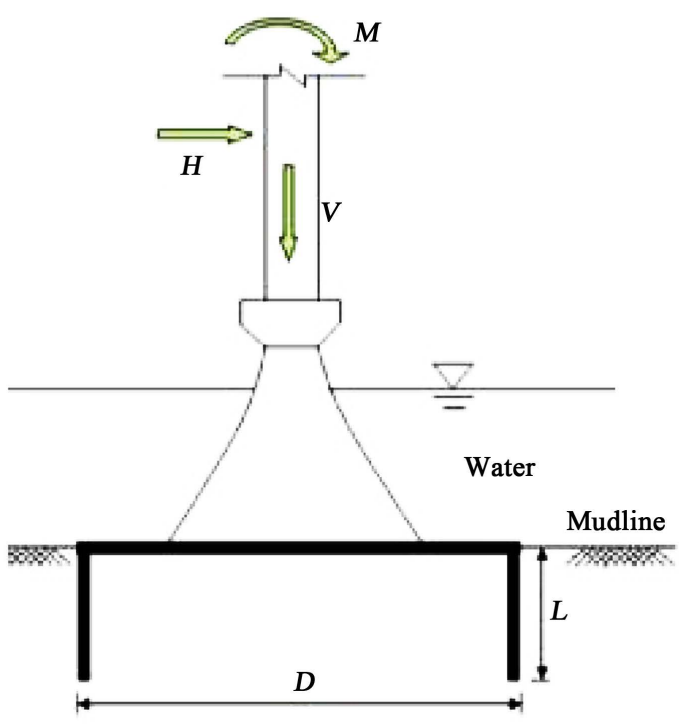

Figure 3. View of a suction bucket (Zhang (2010) [10]).

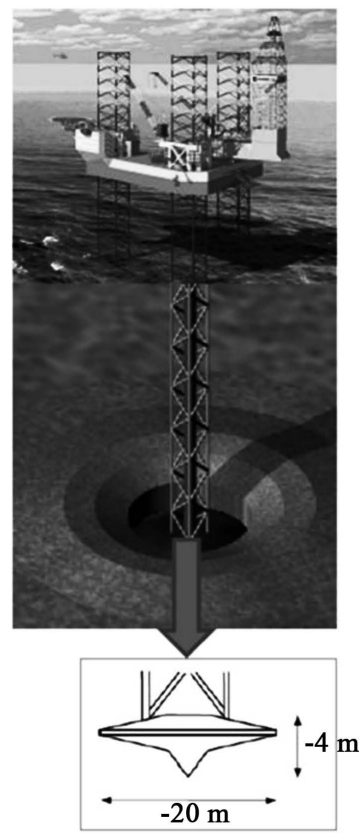

Spudcan

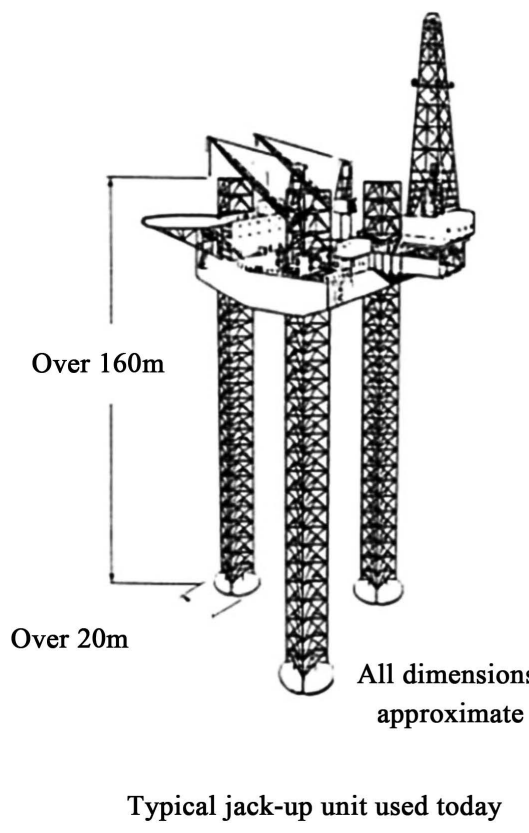

12

Figure 4. Schematic of a Spudcan and Jack-up system in offshore industries (Hambly (1985) [11]).

the breadth of the foundation $(D / B=2)$, they will improve the foundation capacity and by confining the surrounding soil and forming a soil block between the skirts, they will increase the strength of the foundation. Actually, the soil block can act as a rigid body and take part in bearing the pressures and loads from the substructure. These foundations are becoming an extremely prevalent offshore foundation solution for the oil and gas industries (Byrne (2003) [17], Mana (2010) [18], Tripathy (2013) [19], Al-Aghbari (2006) [20]) (Figure 6). 

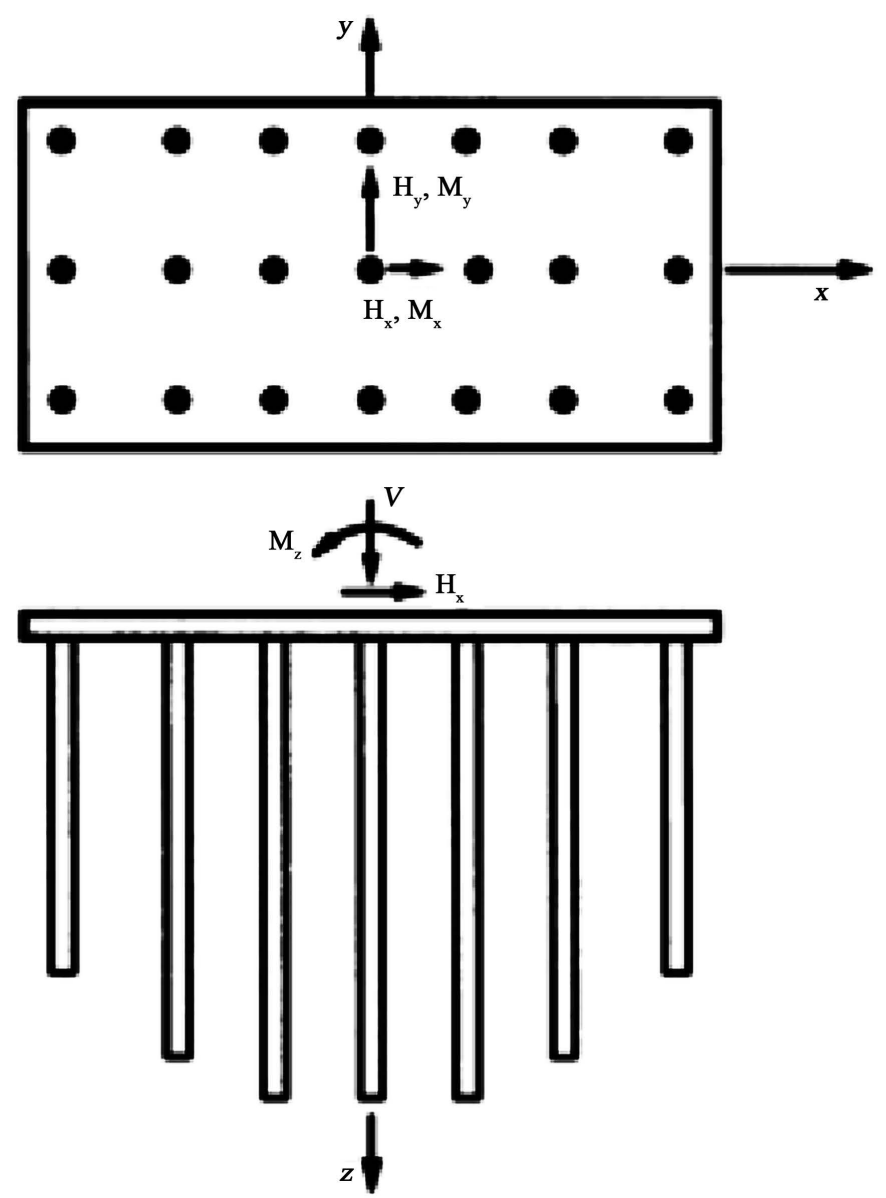

Figure 5. A pile-raft system (Hemsly (2000) [15], Eslami (2012) [16]).

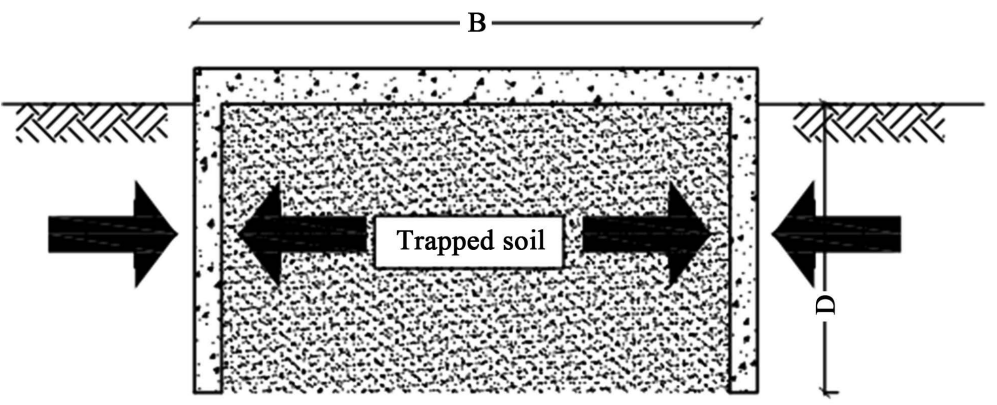

B

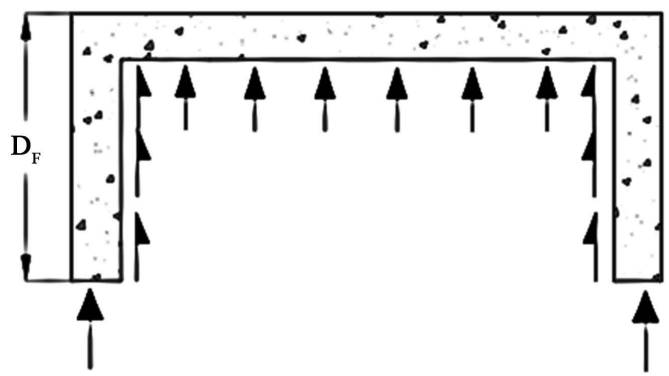

Figure 6. View of a skirted foundation and the soil block. 


\section{Finite Element Analysis}

\subsection{Geometry}

The axisymmetric finite element analysis were performed for the purpose of this study. The model comprises a circular skirted foundation with the breath, B, and depth of, D. In order to observe the different skirt length, a group of embedment ratios $(D / B=0.2,0.3,0.5,0.75,1,1.2$ and 2$)$ were considered in analysis.

For all the analysis, the PLAXIS 2016 finite element software was used. This software is functioning for both offshore and onshore infrastructures and enables us to model advanced materials with different loading conditions of the soil encountered in foundation works.

\subsection{Soil Model}

The soil was defined by a linear elastic-perfectly plastic Mohr-Coulomb model, which represents a first-order approximation of soil behavior (Figure 7). The type of drainage is undrained in a way that, stiffness is modelled using an undrained Young's modulus $E_{u}$ and an undrained Poisson ratio $v_{u}$, and strength is modelled using an undrained shear strength $s_{u}$ and $\varphi_{u}=0$. Excess pore pressures are not explicitly calculated, but are included in effective stresses. Therefore, in that case the Mohr-Coulomb failure criterion reduces to the well-known Tresca criterion.

In the elastic regime, the Young's modulus $\left(E_{u}\right)$ was defined to give a rigidity index, $E_{t} / s_{u}=400$ and a Poisson's ratio, $v_{u}=0.49$. Additional analysis on the variety of rigidity index showed that this did not affect the foundation capacity for the range of problems studied. The shear strength, $s_{u}$ and the stiffness, $E_{u}$ changed linearly with depth as shown in (Figure 8). Plaxis offers an advanced option for the input of clay layers in which the undrained shear strength $s_{u}$ increases with depth.

In order to obtain that condition, the $s_{\text {uinc }}$-value may be used, which increase of cohesion per unit of depth by the equation is as:

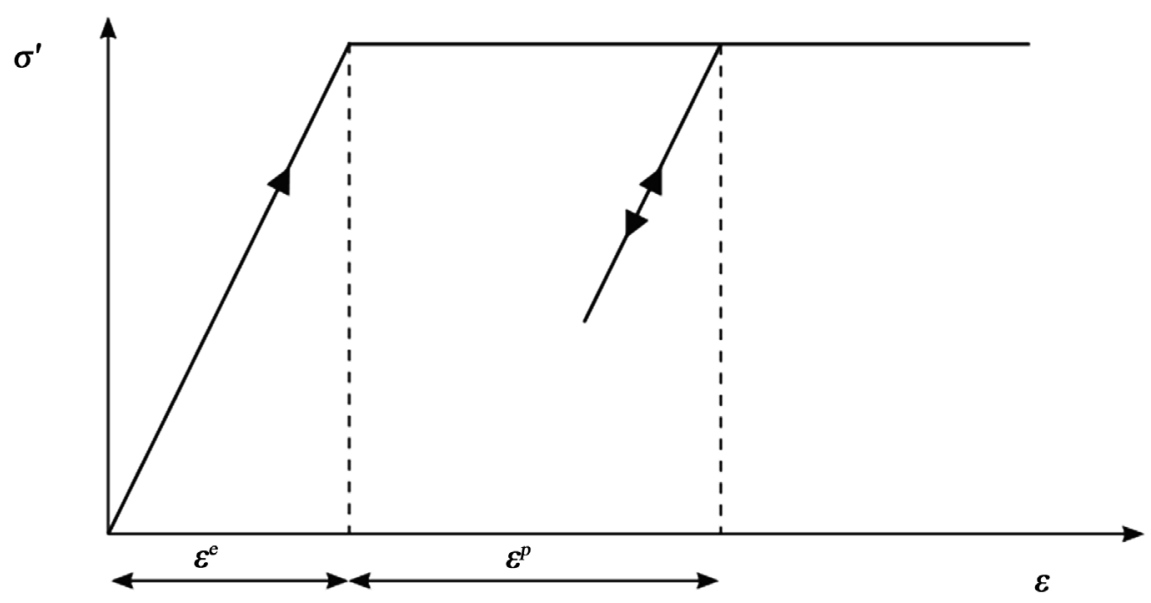

Figure 7. Basic idea of an elastic perfectly plastic model. 


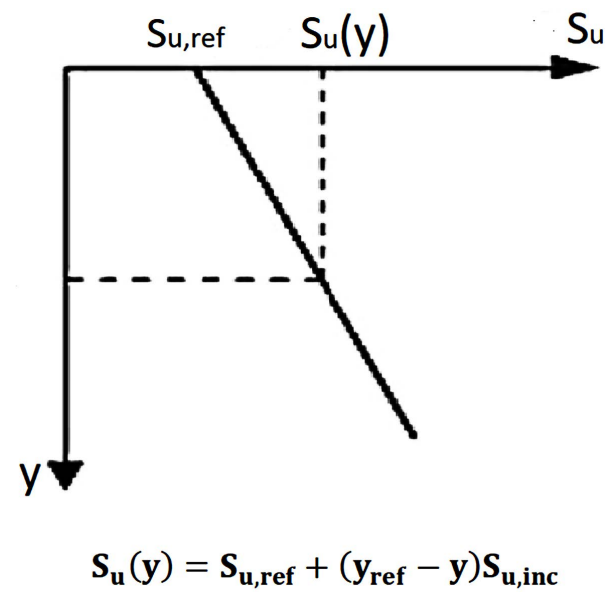

Figure 8. Equivalent shear strength for finite element analysis.

$$
S_{u(y)}=S_{u, r e f}+\left(y_{r e f}-y\right) S_{u, i n c}\left(y<y_{r e f}\right)
$$

where $y$ represents the vertical direction.

In order to account for the increase of stiffness with depth the $E_{\text {inc }}$-value may be used, which is the increase of Young's modulus per unit of depth by the equation as:

$$
E_{(y)}=E_{r e f}+\left(y_{\text {ref }}-y\right) E_{\text {inc }} \quad\left(y<y_{\text {ref }}\right)
$$

where $y$ represents the vertical direction.

Figure 9 shows an specific view of the soil that modelled in PLAXIS sheet.

\subsection{Foundation Model}

The footing was modelled with two approaches. One approach is modelling by the plate elements. Plate elements can be used to model any necessary on-site excavations and foundations. It should be considered that the skirts thickness should be less than the footing's one. The concrete properties applied to the plate elements. Other approach is that the foundation modelled as a rigid body with interfaces which is more common in some cases (Figure 10).

\subsection{Meshes}

Generating meshes is one of the most important parts of designing the footing. Plaxis allows us to perform meshes automatically. The 15-node wedge element is used which is composed of 6-node triangles in horizontal direction and 8-node quadrilaterals in vertical direction. The size of meshes is fine or very fine for exact results. The boundary conditions allowed no vertical or lateral soil movement at the vertical boundaries. Figure 11 shows the finite element mesh for the skirted foundation with $D B=1$ as an example.

\subsection{Loading Condition}

For achieving one of our goals in this paper, which was considering the effects of 


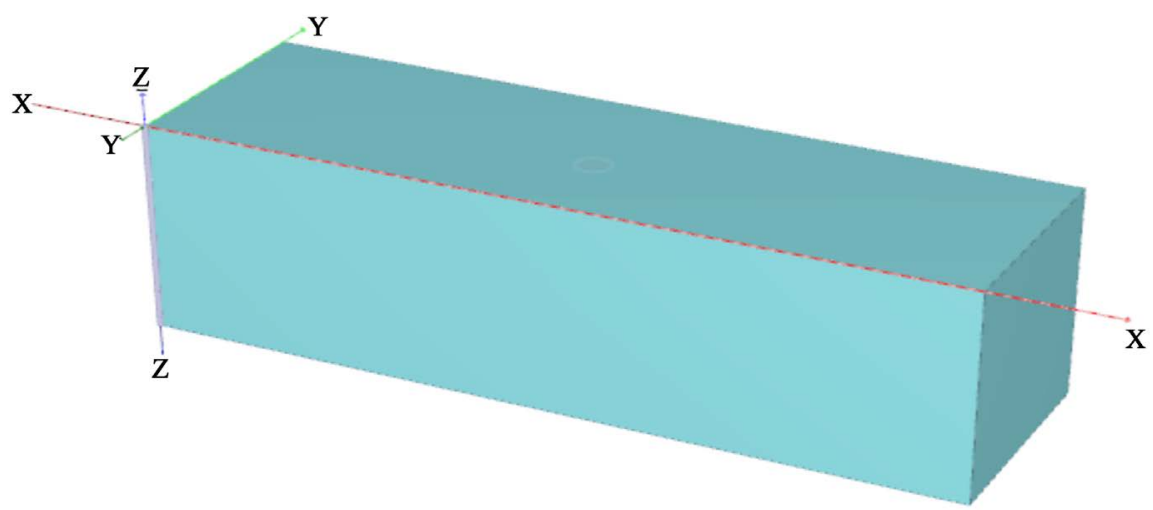

Figure 9. Soil model in PLAXIS 2016.

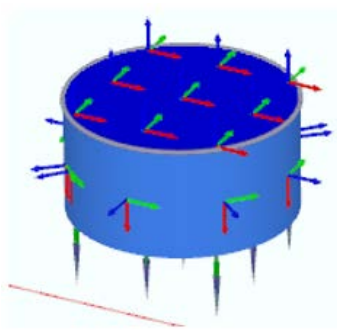

(a)

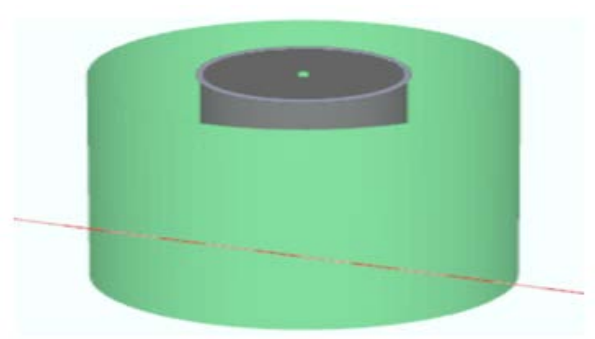

(b)

Figure 10. The foundation model for $D / B=0.5$ (a) plate elements; (b) rigid body with interfaces Meshes.

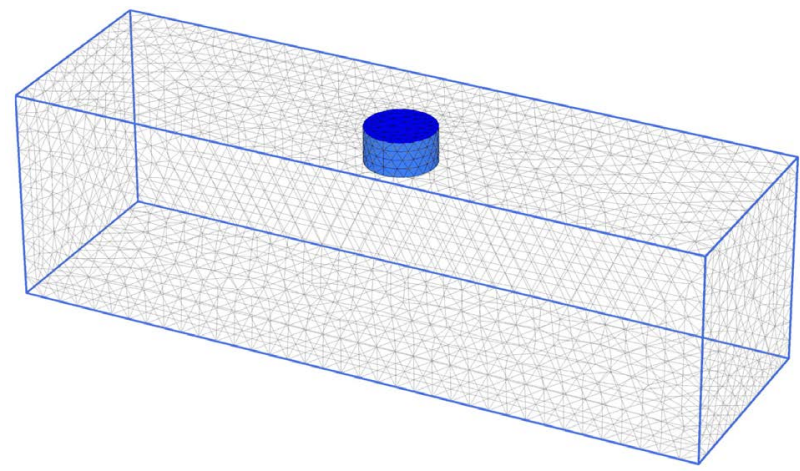

(a)

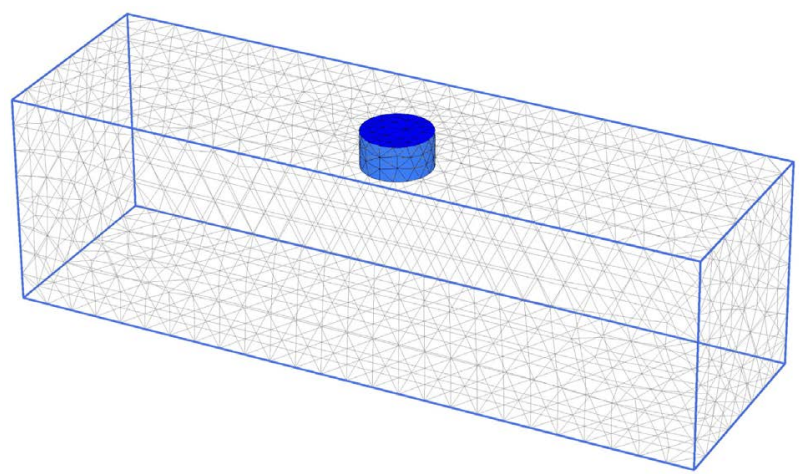

(b)

Figure 11. Mesh generation for foundation with $D / B=0.5$ : (a) very fine; (b) fine. 
displacement on the bearing capacity of the foundation, the bearing capacity was calculated by using displacement control approach. Therefore, footing was loaded by a vertical displacement, which is pulled that to the negative vertical direction. This has been found to give more accurate results for failure conditions than using load control (e.g., Bransby and Randolph, 1999) [1].

\section{Results: Comparison between Skirted Foundations and Shallow Foundations}

First, it is aimed to prove that skirted foundations will improve the foundation capacity in such a remarkable amount. For this purpose, a shallow foundation, a skirted foundation and a block foundation with embedment ratio of 0.5 were analyzed with finite element method in uniform soil. Figure 12 shows the normalized load-displacement curve for every three foundations. All foundations had a vertical displacement, $U_{z}$ into the soil. The breadth of both foundations were 4 and they were modelled as rigid body.

In the chart, it can be seen that when the skirt penetrates, two times of its breadth, into the soil, the vertical capacity of the foundation increases to three times compared with the surface foundation capacity. Figure 13 shows the failure schematic view of the foundations after analyses, which has shown that, skirts help foundation to face a uniform settlement.

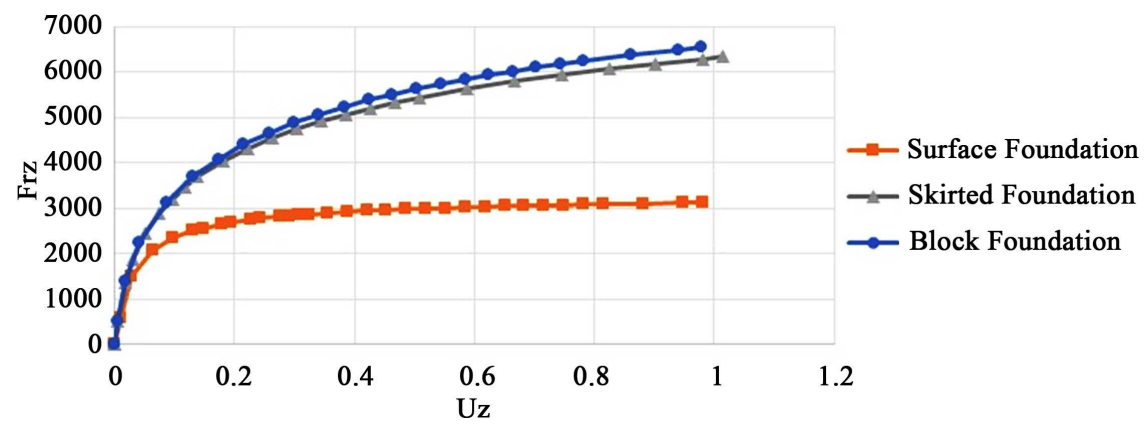

Figure 12. The normalized load-displacement curves for surface foundation and skirted foundation with $\mathrm{D} / \mathrm{B}=2$.

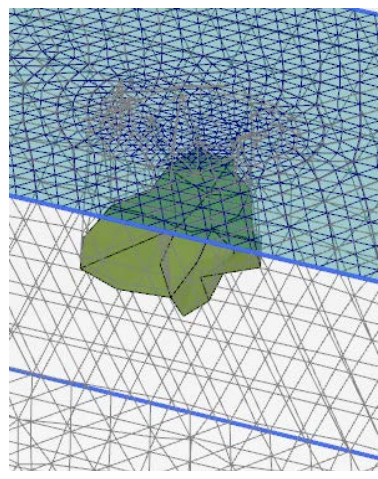

(a)

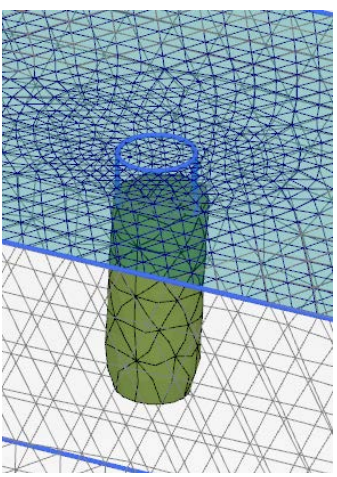

(b)

Figure 13. The deformation schematic view of the foundations after analysis. (a) Surface foundation; (b) skirted foundation $(\mathrm{D} / \mathrm{B}=2)$. 
Figure 13 also shows that skirted foundation can approximately bring the bearing capacity of a block foundation together at the same circumstances and it can be observed that there difference is less than five percent. It means that soil block that confined between the skirts acts as a rigid body and help the foundation to bear the pressures from the substructure(Eid (2012) [21]).

\section{Results: Effect of Embedment Ratio on the Bearing Capacity of Skirted Foundations (Uniform Soil)}

In order to investigate the effect of different length of skirts, the vertical bearing capacity of seven skirted foundations with seven different embedment ratios from 0.2 to 2 were analyzed with finite element method. In this section soil is uniform, which means that the undrained shear strength is constant in depth. Therefore, the foundation capacity, which was normalized by the area of the surface, $\mathrm{A}$ and the undrained shear strength, $\mathrm{Su}$, increases until it reaches to a constant amount. That is the point where the ultimate load is reached. The breadth $\mathrm{B}\left(U_{z} / B\right)$ normalized the displacements. In foundation model, the foundation is modelled with two approaches, which applied in this section too. Figure 14 and Figure 15 show the normalized vertical load-displacement curves for skirted foundations with seven different embedment ratios in uniform soil:

Figure 14 and Figure 15 show the changes in bearing capacity with increasing the embedment ratio in uniform soil. It can be seen that the normalized bearing capacity will improve with increasing in the length of the skirt, however, the general trend and failure points are almost the same and identical. It

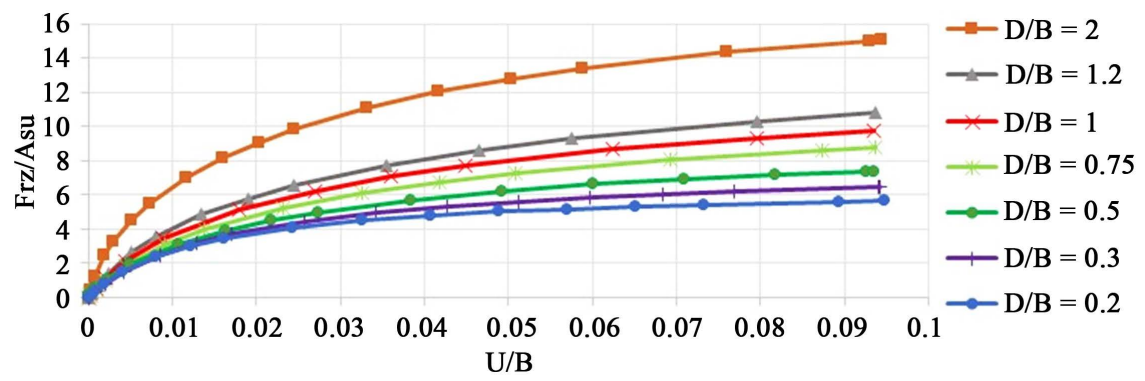

Figure 14. Normalized load-displacement curves for skirted foundation in uniform soil (plate elements).

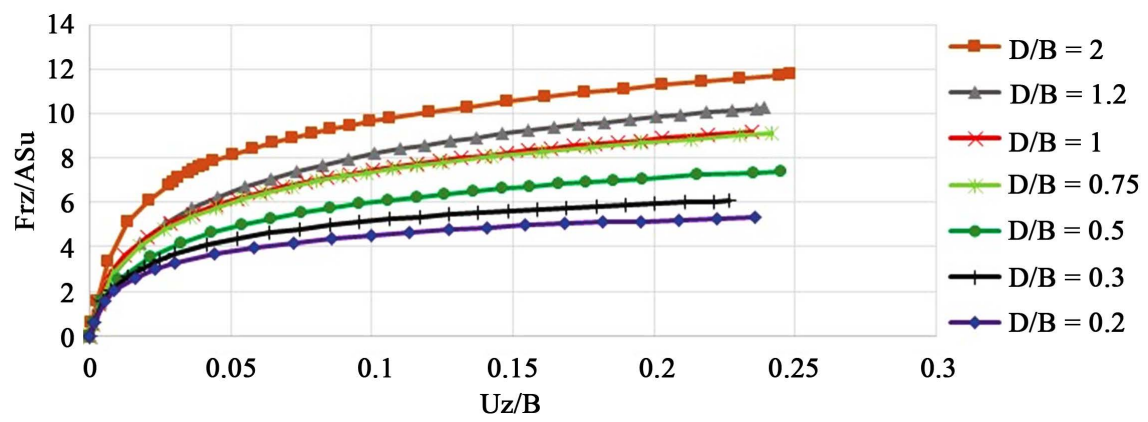

Figure 15. Normalized load-displacement curves for skirted foundations in uniform soil (rigid body with interfaces). 
can also be observed from the figures that type of the foundation have no important effect on the results and there is not any special difference between the shape and even the amount of the ultimate bearing capacity of the foundations. Figure 16 shows the increase of normalized vertical bearing capacity with increase in the embedment ratio.

\section{Results: Effect of Embedment Ratio on the Bearing Capacity of Skirted Foundations (Normally Consolidated Soil)}

In this section soil type is normally consolidated which means that the undrained shear strength will increase with depth with Equation (1) that have introduced in soil model. The method is that the undrained shear strength at the soil surface $\left(S_{u, r e f}\right)$ would consider zero and a uniform increasing strength with depth as typical of the soil conditions of a normally consolidated deposit. Skirted foundations with six different embedment ratios from 0.25 - 2 were analyzed by finite element method for this part investigation and the foundations are modelled as rigid body. Figure 17 shows the normalized vertical load-displacement curves for skirted foundations in normally consolidated soil:

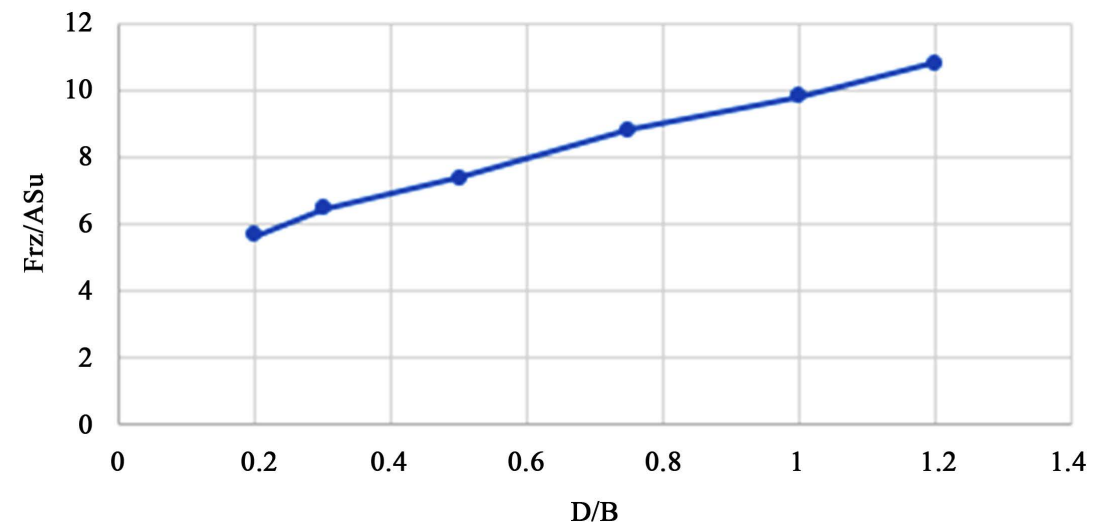

(a)

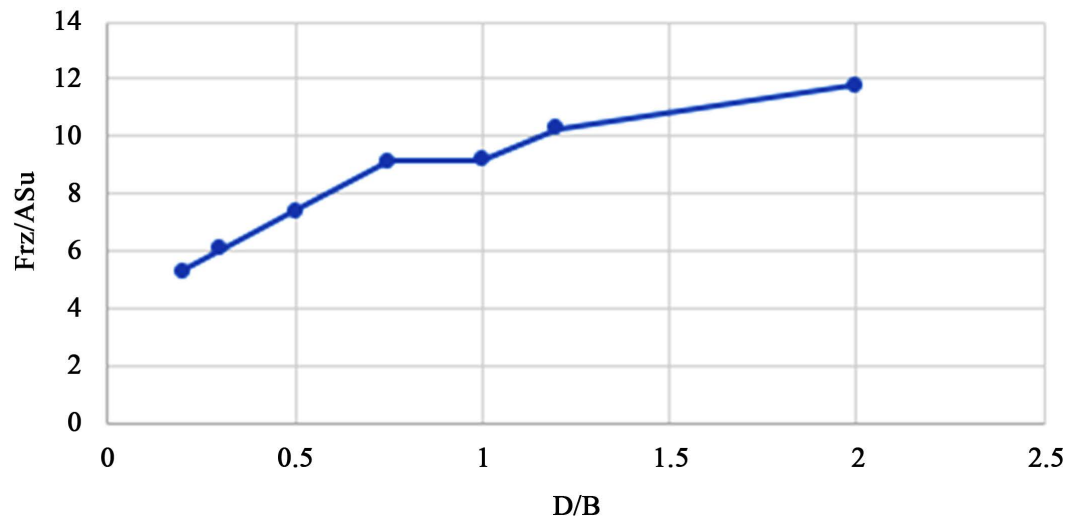

(b)

Figure 16. Variation of normalized bearing capacity with a range of embedment ratios in uniform soil: (a) plate element (b) rigid body. 


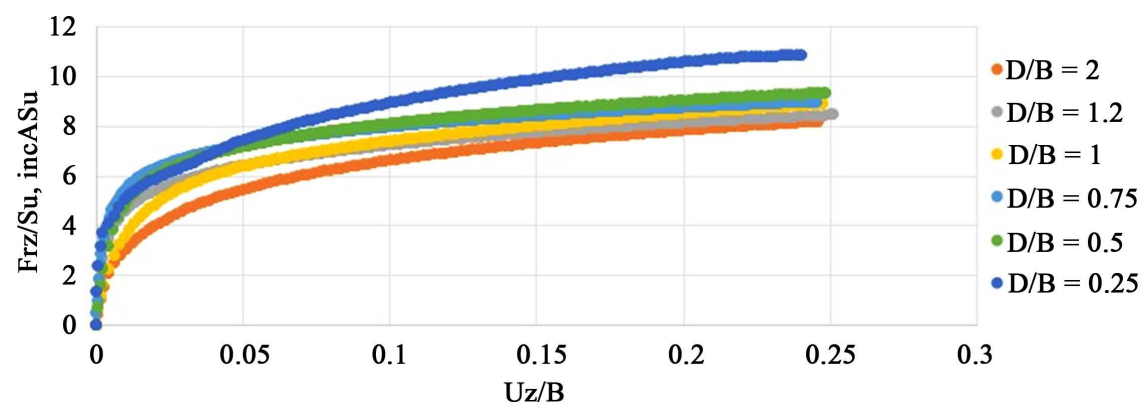

Figure 17. Normalized load-displacement curves for skirted foundations in normally consolidated soil.

It can be seen in Figure 17 that the variation of normalized vertical bearing capacity with increase in embedment ratio in normally consolidated soil is totally different with the one in uniform soil, however, the general trend is still identical. The reason of this difference is that the way that the vertical bearing capacity is normalized, is different from normalization in uniform soil. Here the vertical bearing capacity was normalized by the strength gradient with depth $S_{u, r e f}$ the area of the foundation A and the undrained shear strength at the skirt tip $S_{u_{-}} 0$ which was calculated with the equation below:

$$
\frac{S_{u, i n c} \times B}{S_{u_{0}}}=\frac{1}{D / B}
$$

Therefore, as the amount of undrained shear strength at the skirt tip is different for any embedment ratio and it will increase with the increase of the skirt's length, the variation of normalized bearing capacity is different in normally consolidated soil. Figure 17 also shows that there appears to be small differences between the normalized bearing capacity of skirted foundations when the embedment ratio is $0.5-2$. Figure 18 will show this result in a better way:

\section{Results: Bearing Capacity of Skirted Foundations under Combined Vertical and Horizontal Loading $(v-h)$}

As it was said before, bearing of a foundation under combined loading is more critical than the time it faced with gust absolute vertical or horizontal loading especially in offshore structures. Therefore, in this section, the horizontal load have been surcharged to the vertical load to evaluate the bearing capacity of the foundation in $V-H$ space and reach the failure envelope. To do this, the displacement probe procedure have been employed. A skirted foundation with an embedment depth ratio of 0.5 have been modelled in PLAXIS 2016. The stages of modelling is just like the terms that have said before, the soil was uniform and the foundation has four meters width and has modelled as a rigid body with rough interfaces with soil. a vertical displacement of $U_{z}$ towards down and a horizontal displacement $U_{x}$ to the right has been applied to the foundation on the reference point. Four ratios of vertical displacement to horizontal one $\left(U_{t} / U_{x}\right)$ with two additional analyses for absolute vertical and horizontal bearing 


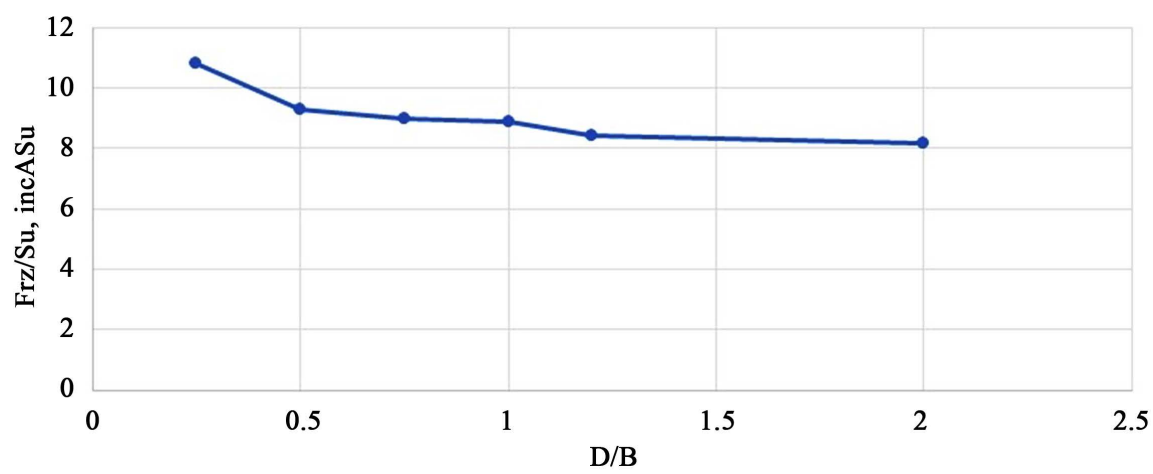

Figure 18. Variation of normalized bearing capacity with a range of embedment ratios in normally consolidated soil.

capacity have used to reach the failure envelope. The results were normalized with the ultimate vertical and horizontal bearing capacity. The results have shown in Figure 19.

Figure 19 show that the failure envelope is similar to a curve with degree of 3 , which leads us to an equation:

$$
\left(\frac{F_{r x}}{F_{r x u l t}}\right)=(-4.537)\left(\frac{F_{r z}}{F_{r z u l t}}\right)^{3}+(4.815)\left(\frac{F_{r z}}{F_{r z u l t}}\right)^{2}+(-1.222)\left(\frac{F_{r z}}{F_{r z u l t}}\right)+1
$$

This equation has $r$-square of 0.994 and tells us which combined loading in $V-H$ space can face the foundation with plastic deformations.

\section{Validation of Results}

For validating the results of load-displacement curves, researches of Yun \& Bransby (2007) [22], have been used as a source. Yun \& Bransby analyzed skirted and embedded foundations with different embedment ratios in ABAQUS 6.2 [22]. Their way of modelling is just identical to the way that have used in this paper, however, in this paper two types of foundations have been applied but they modelled all foundations as rigid bodies. They also did a centrifuge test and an upper bound analysis to confirm their results. Their results have shown that the normalized vertical bearing capacity of a foundation with embedment ratio of 0.5 in uniform soil is 7.03. In this paper, such analysis with same conditions concluded an amount of 7.38 for a skirted foundation with $D / B=0.5$, which means over 90 percent of conformity. Moreover, Yun \& Bransby's research in normally consolidated soil occasioned that the normalized vertical bearing capacity for a skirted foundation with embedment ratio of 1 is 8.23 that when it is comprised with the result of this research in same condition, it would have confirmed a good matching with a percentage of more than 85 [20], The calibration of the results of this study with some of the researches that have been conducted by other researchers has shown in Figure 20 and Figure 21. These researches are consist of analytical, numerical and experimental tests by famous researchers of this context such as: the upper bound analysis of Martin \& Randolph (1999) [23], the centrifuge test and finite element method analysis of Yun 


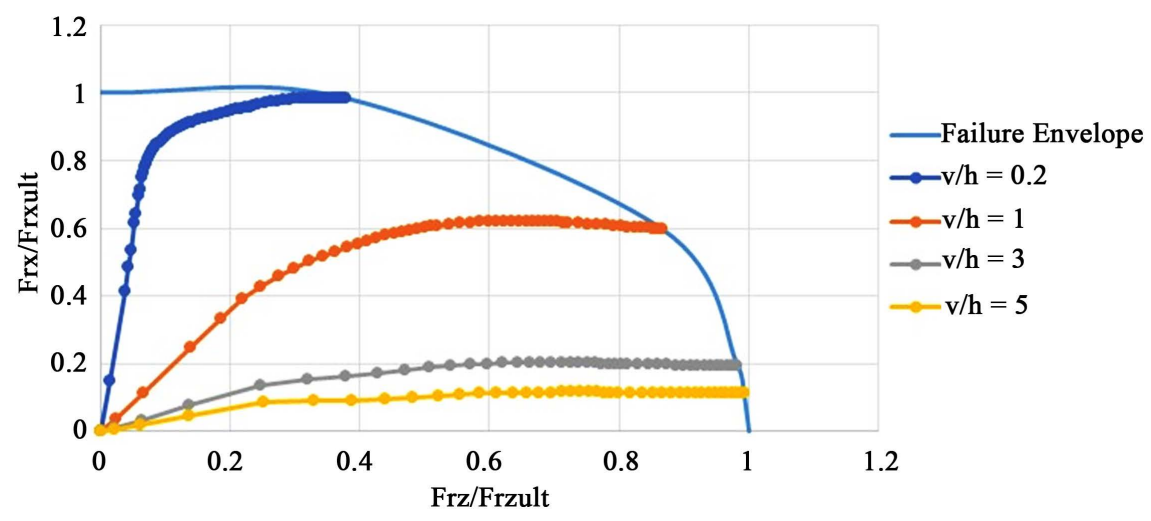

Figure 19. Failure envelope of a foundation with $\mathrm{D} / \mathrm{B}=0.5$ in $V$ - $H$ space.

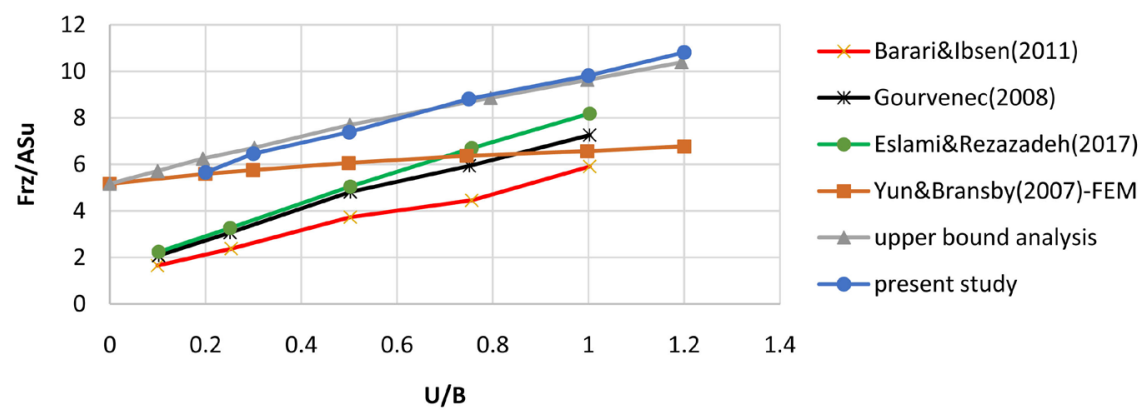

Figure 20. Verification of results of present study with previous researches (uniform soil).

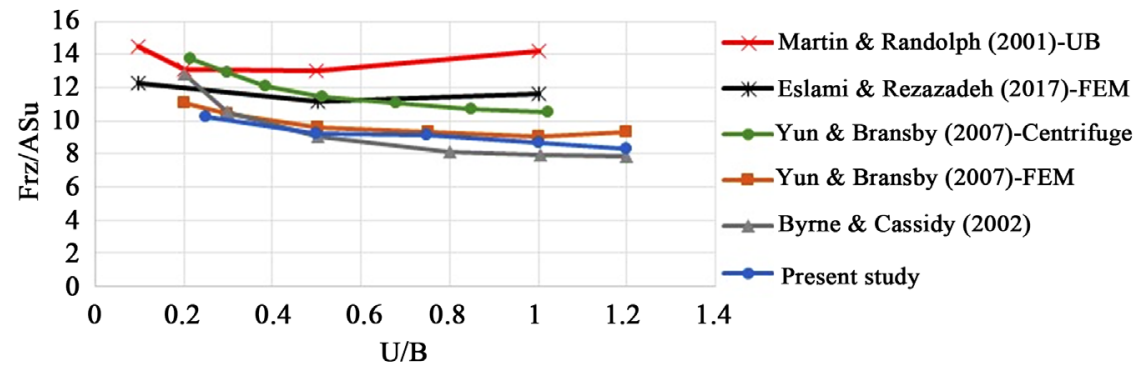

Figure 21. Verification of results of present study with previous researches (normally consolidated soil).

\& Bransby (2007) [22], and the finite element method analysis of Eslami \& Rezazadeh (2017) [4].

These figures can confirm our results about the variation of the normalized bearing capacity by increase in embedment ratio in both uniform and normally consolidated soil.

For validating the results of finite element analysis on skirted foundations under combined loading of vertical and horizontal loading, the researches of Bienen et al. (2012), have been used. Their studies are on bearing capacity of skirted foundations on uniform soil under combined loading [24]. Figure 22 shows the calibration of $V-H$ failure envelope that they have presented with the one that have concluded in this study. The comparison between this figure with the failure envelope that concluded by the finite element analyzes in this paper, 


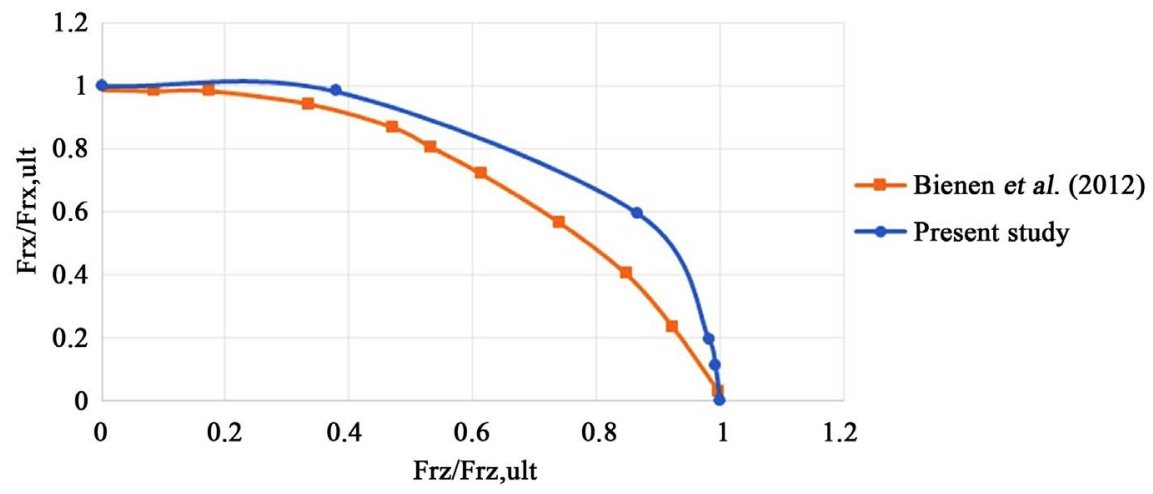

Figure 22. Calibration of the $V$ - $H$ failure envelope.

has shown that the schematic view of a failure envelope in $V$ - $H$ space is similar to a curve or a quadrant (Yun (2007) [25]).

\section{Conclusions}

Various types of semi-deep foundations have been introduced with their properties and load conditions.

Several finite element analysis have been done on skirted foundations with various embedment ratios in uniform and normally consolidated soil and foundations with plate elements and rigid bodies by PLAXIS 2016. Moreover, a skirted foundation with $D / B=0.5$ in uniform soil has been analyzed under combined loading of vertical and horizontal loading in $V-H$ space and the failure envelope has been presented.

Skirted foundations improve the bearing capacity of shallow foundations up to 3 times depend on their embedment ratio by penetrating to the depth of the soil. They also can supply the bearing capacity of an equivalent embedded foundation, which confirms that the trapped soil between the skirts can act as a rigid body and take part in bearing forces and pressures.

The effect of the length of skirt on the bearing capacity has been investigated by modelling and analyzing the skirted foundation in PLAXIS 2016 and the results have been presented by normalized load-displacement curves. The curves have shown that in uniform soil, the normalized vertical bearing capacity would increase with increase in embedment ratio, however, in normally consolidated soil, the normalized vertical bearing capacity for the embedment ratios more than 0.5 is the same and it is because of the normalization and the changing in undrained shear strength with depth.

The verification of the results of various normalized vertical bearing capacity with increase in embedment ratio with other analytical, numerical and experimental researches showed a good conformity.

The bearing capacity of a skirted foundation under combined vertical and horizontal loading in $V$ - $H$ space has been analyzed by modelling a skirted foundation with $D / B=0.5$ in uniform soil for four different ratios of vertical displacement to horizontal one and the failure envelope and an equation has been pre- 
sented, which shows a limited forces that the foundation can bear without any plastic deformations.

The $V$ - $H$ failure envelope has been validated by the research of Bienen et al. (2012), and it has been observed that both have a same schematic view [24].

\section{References}

[1] Bransby, F. and Randolph, M. (1999) The Effect of Embedment Depth on the Undrained Response of Skirted Foundations to Combined Loading. Soils and Foundations, 39, 19-33. https://doi.org/10.3208/sandf.39.4_19

[2] Bransby, M. and Yun, G.-J. (2009) The Undrained Capacity of Skirted Strip Foundations under Combined Loading. Géotechnique, 59, 115-125. https://doi.org/10.1680/geot.2007.00098

[3] Mana, D., Gourvenec, S. and Randolph, M. (2010) A Numerical Study of the Vertical Bearing Capacity of Skirted Foundations. Proc. 2nd Int. Symp. Front. Off. Geotech. (ISFOG), Perth, 433-438.

[4] Rezazadeh, S. and Eslami, A. (2017) Bearing Capacity of Semi-Deep Skirted Foundations on Clay Using Stress Characteristics and Finite Element Analyses. Marine Georesources \& Geotechnology, 1-15. https://doi.org/10.1080/1064119X.2017.1361488

[5] Golder, H. (1976) The Canadian Manual on Foundation Engineering: Book Review. Canadian Geotechnical Journal, 13, 499-504. https://doi.org/10.1139/t76-048

[6] Gupta, S.C. (2007) Raft Foundation Design and Analysis with a Practical Approach. New Age International.

[7] Saleh, N.M., Alsaied, A.E. and Elleboudy, A.M. (2008) Performance of Skirted Strip Footing Subjected to Eccentric Inclined Load. EJGE, 13, 1-33.

[8] Barari, A. and Ibsen, L.B. (2012) Undrained Response of Bucket Foundations to Moment Loading. Applied Ocean Research, 36, 12-21. https://doi.org/10.1016/j.apor.2012.01.003

[9] Ibsen, L.B., Barari, A. and Larsen, K.A. (2015) Effect of Embedment on the Plastic Behavior of Bucket Foundations. Journal of Waterway, Port, Coastal, and Ocean Engineering, 141, 06015005. https://doi.org/10.1061/(ASCE)WW.1943-5460.0000284

[10] Zhang, J., Chen, Z. and Li, F. (2010) Three Dimensional Limit Analysis of Suction Bucket Foundations. Ocean Engineering, 37, 790-799.

https://doi.org/10.1016/j.oceaneng.2010.02.017

[11] Hambly, E.C. (1985) Punch-Through Instability of Jack-Up On Seabed. Journal of Geotechnical Engineering, 111, 545-550. https://doi.org/10.1061/(ASCE)0733-9410(1985)111:4(545)

[12] Mekbib, M. (2004) Performance of Piled Raft Foundations For Addis Ababa Soils. Addis Ababa University.

[13] Davis, E. and Poulos, H. (1972) The Analysis of Piled Raft Systems. Australia Geotechnique Journal, 2, 21-27.

[14] Eslami, M., Aminikhah, A. and Ahmadi, M. (2011) A Comparative Study on Pile Group and Piled Raft Foundations (PRF) Behavior Under Seismic Loading. Computational Methods in Civil Engineering Journal (CMCE), 2.

[15] Hemsley, J.A. (2000) Design Applications of Raft Foundations. Thomas Telford. https://doi.org/10.1680/daorf.27657 
[16] Eslami, A., Veiskarami, M. and Eslami, M. (2012) Study on Optimized Piled Raft Foundations (PRF) Performance with Connected and Non-Connected Piles-Three Case Histories. International Journal of Civil Engineering, 10, 100-111.

[17] Byrne, B. and Houlsby, G. (2003) Foundations for Offshore wind Turbines. Philosophical Transactions of the Royal Society of London A: Mathematical, Physical and Engineering Sciences, 361, 2909-2930. https://doi.org/10.1098/rsta.2003.1286

[18] Mana, D.S., Gourvenec, S. and Martin, C.M. (2010) Critical Skirt Spacing for Shallow Foundations under General Loading. Journal of Geotechnical and Geoenvironmental Engineering, 139, 1554-1566. https://doi.org/10.1061/(ASCE)GT.1943-5606.0000882

[19] Tripathy, S. (2013) Load Carrying Capacity of Skirted Foundation on Sand.

[20] Al-Aghbari, M. and Mohamedzein, Y.-A. (2006) Improving the Performance of Circular Foundations Using Structural Skirts. Proceedings of the Institution of Civil Engineers- Ground Improvement, 10, 125-132. https://doi.org/10.1680/grim.2006.10.3.125

[21] Eid, H.T. (2012) Bearing Capacity and Settlement of Skirted Shallow Foundations on Sand. International Journal of Geomechanics, 13, 645-652. https://doi.org/10.1061/(ASCE)GM.1943-5622.0000237

[22] Yun, G. and Bransby, M. (2007) The Undrained Vertical Bearing Capacity of Skirted Foundations. Soils and Foundations, 47, 493-505. https://doi.org/10.3208/sandf.47.493

[23] Hu, Y., Randolph, M. and Watson, P. (1999) Bearing Response of Skirted Foundation on Nonhomogeneous Soil. Journal of Geotechnical and Geoenvironmental Engineering, 125, 924-935.

https://doi.org/10.1061/(ASCE)1090-0241(1999)125:11(924)

[24] Bienen, B., et al. (2012) Numerical Modelling of a Hybrid Skirted Foundation under Combined Loading. Computers and Geotechnics, 45, 127-139. https://doi.org/10.1016/j.compgeo.2012.05.009

[25] Yun, G. and Bransby, M.F. (2007) The Horizontal-Moment Capacity of Embedded Foundations in Undrained Soil. Canadian Geotechnical Journal, 44, 409-424. https://doi.org/10.1139/t06-126 